\title{
IDENTIDADES COLETIVAS E MOBILIZAÇÃO DE IDENTIDADES*
}

\author{
Klaus Eder
}

\section{Introdução}

O Estado nacional é um mecanismo de domesticação dos sentimentos coletivos, que atua unindo o povo em uma nação. Isso permanece verdadeiro mesmo depois das mais recentes, e em parte violentas, formações de Estados nacionais na Europa - Estados que surgiram da dissolução dos últimos impérios no Sudeste e no Leste do Continente. Paradoxalmente, a Europa revelou-se ao mesmo tempo pioneira e retardatária no processo de construção do Estado nacional. ${ }^{1}$ Podemos, assim, partir da premissa de que o Estado nacional tornou-se um fenômeno universal, um ator coletivo universal representando um povo civilizado, isto é, uma nação.

* Conferência proferida no XXVI Encontro Anual da Ampocs, em Caxambu, MG. Texto traduzido por André Villalobos
No curso de sua universalização, o Estado nacional depara-se com um paradoxo: tornar-se um ator central no processo de globalização enquanto sua unidade cultural, a nação, é solapada por formas "étnicas" de pertencimento que não mais coincidem com as fronteiras nacionais. O que resta é o Estado nacional sem a nação. Isso constitui um desafio para todas as teorias que afirmam que os Estados, isto é, os sistemas de decisão política, devem estar inseridos num mundo da vida, que proporciona a base da solidariedade, da confiança ou da identidade. Este suposto, de que os Estados necessitam de uma base cultural, é mais claramente afirmado por Habermas (1984, 1987), quando argumenta que qualquer sistema social está ligado a um mundo da vida que lhe dá legitimidade. Mas é também parte do antigo e do novo comunitarismo, e central para a sociologia parsoniana ou para a concepção de dominação legítima em Weber. 
As teorias do Estado nacional baseiam-se na observação de uma íntima associação entre unidades simbólicas e unidades sistêmicas: o Estado identificado com o povo. Essa associação nunca se realizou historicamente, mas funcionou como uma idéia diretriz ao longo dos séculos. No mundo contemporâneo, observamos uma dissociação entre as estruturas sistêmicas que governam a reprodução da dominação política e econômica, tanto no âmbito nacional como transnacional e subnacional, por um lado, e as estruturas geradoras de identidades culturais, de sentimentos de pertencer e de entusiasmos coletivos, de outro. A articulação entre ambas torna-se mais contingente e exige que tenhamos novas idéias sobre as conexões teóricas entre os sistemas de ação e as pessoas que neles atuam. É necessário que as teorias dêem conta das conseqüências dessa dissociação para o Estado e para o mundo da vida.

Acredito que, em virtude dessa dissociação, a forma do Estado está sendo afetada: o Estado nacional está se tornando um ator racional em escala global, como ocorre com as empresas econômicas. Tal dissociação tem conseqüências também para o modo de pertencimento coletivo, para o povo: ela abre a caixa de Pandora da mobilização de identidades, de sentimentos de pertencimento para além do Estado nacional, seja acima dele (como as formas transnacionais de mobilização de identidades) ou abaixo (como as formas regionais ou locais de mobilização de identidades).

Ambas as conseqüências são teoricamente desafiadoras. O que acontece com o Estado que não pode mais contar com o consentimento do povo, com o "plebiscito democrático cotidiano" (para parafrasear Renan)? Pode transformar-se num corpo deliberativo auto-sustentável de especialistas, capaz de influenciar a opinião pública por meio da política simbólica. O que acontece com o outro lado do par, o povo? Pode este ainda se tornar um demos (corpo democrático) ou tende a se dissipar numa série de demoi ou - pior ainda - numa série de buscas identitárias por comunidade?2 Ou temos de imaginar que as comunidades devem ser substituídas por alguma espécie mais abstrata ou mais instrumental de união?
Isso é ainda mais desafiador quando procuramos observar o efeito combinado dessas conseqüências, isto é, quando analisamos a relação entre o Estado e o povo. O que acontece com o Estado quando tem de lidar com grupos culturais antagônicos no interior de suas fronteiras? Tais situações podem ser constatadas em Estados nacionais com uma coletividade dividida - bons exemplos na Europa são a Bélgica e a Suíça - ou com uma população de desconhecidos.

De modo a não confrontá-los com demasiadas interrogações (sem finalmente apresentar qualquer resposta), focalizarei minha palestra principalmente na seguinte questão: Como se apresentam as identidades coletivas "desacopladas"? Em poucas palavras, argumentarei que há um tema dominante - o "desacoplamento" entre o Estado e a nação e um contra-tema - a lógica autônoma da mobilização de identidades. ${ }^{3}$ Em seguida, esses temas serão desenvolvidos de maneira histórica, sistemá tica e, finalmente, concreta, utilizando-se a União Européia como o caso ilustrativo da problemática estudada. Por fim, discutirei se o Estado nacional seria ainda a forma apropriada para domesticar os sentimentos coletivos. Não se trata de imaginar o desaparecimento do Estado nacional (este continuará a existir), mas de saber se uma de suas funções centrais - transformar um sentimento coletivo num demos civilizado - será assumida por arranjos institucionais para além dele.

\section{Laço histórico entre o Estado e o povo}

\section{Contingência}

Historicamente, deparamo-nos com um interessante paradoxo na construção do Estado nacional: o Estado, criado pelo povo, transformou-se em algo do qual o povo emergiu. O povo esteve na origem do Estado moderno, seja por meio de um contrato, seja através de outras formas de construção da vontade coletiva (incluindo a de ser súdito de um governante esclarecido). E então, surgido do povo, o Estado transformou-o num corpo político, a nação. ${ }^{4}$ Esta transubstanciação (verdadeiramente mística) do povo em nação, 
isto é, numa outra espécie de povo, está na base do Estado moderno, que se constituiu no curso de vagas revolucionárias ou de reformas democráticas. ${ }^{5}$

A conexão entre Estado e nação foi objeto de muita discussão entre filósofos e teóricos políticos a respeito das qualidades desse corpo emergente, descrito idealmente como um demos, um povo capaz de ser seu próprio soberano. A construção desse demos baseou-se na língua e nos valores culturais compartilhados que asseguravam o caráter reconhecível do povo. Diferenças de classe, regionais e de gênero foram mediadas por um novo modo de pertencer: a cidadania. ${ }^{6}$ Esta baseou-se num vínculo exclusivo, a saber, ser parte de uma nação. Pertencimento e vinculação são os dois processos relacionados por meio dos quais foi construída a nação.

Podemos descrevê-los em termos da criação de um espaço social de comunicação no qual são institucionalizados códigos específicos de distinção entre um "nós" coletivo e um "outro" coletivo.' O resultado é a construção de uma identidade coletiva que se manifesta como a idéia de um ego capaz de ter ou expressar uma vontade coletiva. Essa identidade permite superar interesses particulares, criar a disposição de pagar impostos, de entregar os filhos a instituições educacionais controladas pelo Estado e de, até mesmo, morrer pelo Estado. As pessoas agora fazem essas coisas não porque alguma autoridade externa as obrigue, mas porque acreditam que todos devem assim proceder. Quem estuda a evasão fiscal, o absenteísmo escolar ou a deserção, bem sabe o quão difícil é esta solução. O Estado nacional é uma "instituição de baixa probabilidade", o que explica por que precisou de uma forte identidade coletiva para superar tais atos de defecção bastante prováveis.

Ao mesmo tempo, as sociedades criaram um novo problema, qual seja, o de identidades coletivas pautadas pela lógica do conflito de grupo. Essa lógica pressupõe um confronto de identidades que pode resultar em enfrentamentos violentos, um padrão que conhecemos tanto na Europa do passado como na dos anos de 1990. A domesticação das identidades coletivas é algo difícil de ser alcançado, mas parece que a instituição do Estado nacional conseguiu fazê-lo (pelo menos na Euro$\mathrm{pa}$, a proporção de guerras diminuiu significativamente nos últimos sessenta anos).

Isso tudo é plausível como um balanço descritivo, mas existiria uma razão teórica para que o Estado moderno necessite de uma identidade coletiva?

Identidades versus interesses: uma primeira proposição teórica

As identidades coletivas proporcionam um princípio de integração social. Outro princípio é constituído pelos interesses. Há uma complementaridade teórica específica a ser identificada na relação entre identidades e interesses. As identidades definem fronteiras em relação ao mundo exterior; excluem os outros. ${ }^{8}$ Os interesses conduzem a estratégias que incluem os outros mediante um cálculo racional, ou seja, levam a prover um mundo de pessoas suficientes para dele se beneficiarem. As identidades definem as fronteiras de um espaço em que se incluirão os interesses. Estes, por sua vez, rompem fronteiras, ligando as pessoas como indivíduos que seguem suas estruturas de preferências e transgridem as obrigações e as normas coletivamente compartilhadas. Tratase da função liberadora da ação racional, já observada pela sociologia histórica comparada, segundo a qual os entrepostos de comércio, as cidades comerciais e as culturas mercantis parecem ter desenvolvido os regimes mais liberais, embora instáveis. " Esse aspecto liberador transformou-se na ideologia neoliberal, segundo a qual o bem coletivo é considerado resultante da ação baseada no interesse próprio.

A proposta teórica em que se baseiam as observações que se seguem não opõe identidades e interesses, antes supõe sua constituição recíproca. ${ }^{10}$ Esta proposta começa com um enunciado defendido pelo neo-institucionalismo econômico: a busca racional de interesses cria relações sociais instáveis. Tais relações precisam, portanto, de instituições fortes para criar laços sociais estáveis. As instituições econômicas não podem fazê-lo. Isso é, 
exatamente, o que compete às instituições políticas, que impõem restrições aos atores em sua busca racional de interesses - como um sentido de justiça ou uma identidade coletiva. Esta é a lógica da appropriateness ${ }^{11}$, como argumentaram enfaticamente March e Olsen (1984, 1989). A solução moderna foi um Estado baseado numa identidade nacional que proporcionou o arcabouço para o desenvolvimento do capitalismo.

Disso se segue uma proposição teórica: é a configuração particular de interesses e identidades o que explica a dinâmica das relações sociais num dado espaço social e num determinado tempo. O Estado nacional moderno é um caso particular dessa combinação de identidades e interesses. Pode-se dizer que se trata mesmo do caso ideal de sua convergência: a busca racional do interesse é maximizada onde existe um Estado que produz uma percepção compartilhada de sua appropriateness, isto é, uma identidade coletiva. ${ }^{12}$ O demos nacional foi a ficção ideal de uma identidade asseguradora da inclusão - algumas vezes da inclusão igualitária - dos interesses de um povo. Essa foi a solução encontrada pelo Estado nacional em sua evolução.

\section{A dissociação entre interesses nacionais e sentimentos coletivos}

Esta ficção ideal tem dois modos de existência: o material e o simbólico. Como algo material, raramente conseguiu ser realizada. Como dispositivo simbólico, sobreviveu por longos períodos e forneceu o suporte ideológico para o processo de modernização, especialmente para o processo de democratização e de desenvolvimento capitalista. $O$ modo de existência simbólico das instituições modernas gerou o discurso moderno sobre "o" povo.

Minha hipótese é a de que estamos vivendo o apogeu do Estado nacional, mas podemos também já ser observadores da sua superação. Meu argumento empírico é o de que o modo simbólico de existência de um povo, o demos, foi posto em questão por vários processos, como a diferenciação de laços sociais e os discursos que já não dão por certa a unidade simbólica do povo.
Ademais, surgiram identidades coletivas que atravessam as estruturas de vinculação e de pertencimento constitutivas do Estado nacional. Em suma, a nação dissociou-se do Estado e novas identidades surgem paralelamente às nacionais. As razões para essa dissociação são:

- Reflexividade: conhecimento de que a nação é algo construído.

- Diferenciação étnica: competição entre identidades coletivas igualmente legítimas.

- Migração: surgimento da formação de identidades coletivas secundárias.

- Permissão de residência a estrangeiros: aumento da cidadania parcial, que cria modos de pertencimento cruzados, solapando assim a idéia de uma filiação unitária ao Estado.

Essa dissociação produziu uma "dissociação secundária", negligenciada em grande parte do debate sobre novas identidades coletivas, a saber, a dissociação entre o ser membro de um Estado como cidadão e o estar integrado num povo através de laços comunitários. Em outras palavras, o desacoplamento entre o ser cidadão e o sentimento de identidade coletiva. Podemos pertencer formalmente a um Estado e, ainda assim, sentirmo-nos parte de uma comunidade cujos limites não coincidem necessariamente com o âmbito por ele abrangido. Podemos, por exemplo, nos identificar como parte da humanidade de maneira geral, o que evidentemente cruza as fronteiras do Estado nacional. Intelectuais e burgueses podem ter uma identificação cosmopolita; trabalhadores podem estar mais marcados pelo localismo, e vice-versa.

Essa dissociação "secundária" separa a dinâmica das identidades da dinâmica dos interesses. É preciso compreender as conseqüências desse processo. Por isso, no próximo passo do desenvolvimento de minha argumentação, procurarei dar uma base teórica à minha descrição "sistemática” dessas conseqüências. 


\section{A transformação da relação entre o Estado e o demos}

O Estado nacional como ator coletivo no processo de globalização

Contrariamente à hipótese de que o Estado nacional estaria perdendo terreno, acredito que ele está ganhando espaço, mas não como identificado com o povo, e sim como um ator coletivo com interesses "nacionais". O desacoplamento entre identidades e interesses possibilitou transformar o Estado nacional em um ator coletivo racional, um grupo de interesse. O Estado nacional torna-se um ator global, como ocorre com as firmas transnacionais. Esse é, provavelmente, o fenômeno básico denotado pelo termo globalização: os Estados nacionais competem em escala global, constituindo-se em grupos de interesse globais diferenciados dos atores econômicos. Afirmar que, uma vez iniciada, essa competição produz sistemas de posições desiguais (como, por exemplo, o mundo da OECD e o dos que não pertencem àquela organização) não elimina o argumento de que a ação orientada pelo interesse torna-se o modo predominante de existência do Estado nacional.

Teoricamente, o Estado nacional, pelo menos no Ocidente, está racionalizado no sentido weberiano: trata-se de um ator coletivo que barganha e negocia com outros Estados nacionais para garantir vantagens relativas e que assegura o consentimento popular por meio da demonstração de êxito da ação de interesse próprio contra outro Estado nacional. Os próprios indivíduos são consideradas atores racionalmente interessados.

Esta transformação do Estado moderno em grupo de interesse é estimulada pelo surgimento de coalizões entre Estados, visando à minimização recíproca de custos transacionais, de modo a se tornarem atores mais poderosos na arena global. Um caso particular desse tipo de coalizão desenvolveu-se na Europa com o Mercado Comum e, posteriormente, com a União Européia. Essa realidade institucional emergente foi concebida (pelo menos no início) como uma mera Zweckverband, um tipo de instituição empresarial. ${ }^{13}$
O que restou do demos? Um conjunto de atores, movidos por seus próprios interesses, que não mais compartilham o sentido de laços coletivos. Pode-se observar, contudo, a persistência de uma busca latente por vínculos. A transformação do Estado em um poderoso grupo de interesse leva apenas a que os sentimentos coletivos dele se desacoplem. Liberadas, as identidades coletivas nacionais passam a competir com outras reivindicações de identidade coletiva. A afirmação da identidade nacional perde seu monopólio e encontrase agora atuando, por assim dizer, num mercado de reivindicações de identidades coletivas.

\section{A lógica das reivindicações de identidade: uma segunda proposição teórica}

Essa liberação obriga-nos a pensar com mais atenção a lógica das reivindicações de identidade, que difere da que preside à busca racional de interesses. Como explicá-la? As reivindicações de pertencimento a algum "nós" baseiam-se em narrativas (como as narrativas de vitórias ou derrotas), por meio das quais um povo se reconhece como coletividade. Por intermédio de tais narrativas, um povo define um mundo da vida compartilhado, que distingue claramente quem é parte dele e quem não é. Essas narrativas constituem poderosos sinalizadores de fronteiras de exclusão. Além disso, elas reivindicam um bem particular: uma identidade entendida como um bem coletivo. A identidade não é algo que se negocie com outros; tratase de um bem indivisível. Não há termo comum entre identidades. Quando ocorre uma colisão entre reivindicações de identidade, podem-se imaginar idealmente dois resultados: reconhecimento recíproco ou mútua aniquilação. Em outras palavras, ou ambas se reconhecem plenamente, o que significa dizer que afirmam sua diferença e requerem tolerância, ou entram em conflito até que atinjam o ponto da completa separação ou da aniquilação recíproca. Na realidade, esses conflitos situam-se em algum lugar entre esses dois pontos ideais que sugerem os extremos de uma série de possibilidades, no interior da qual se dão as especificidades dos choques de identidade nos 
casos concretos. Essa teoria ajuda-nos a explicar por que as identidades coletivas são tão importantes para o Estado: elas fornecem uma narrativa integradora. Explica também por que tais identidades precisam de uma forte inserção institucional: as instituições criam o monopólio de uma narrativa, evitando assim guerras de identidade dentro do Estado. Isso implica, ainda, a supressão de narrativas competidoras - até mesmo violentamente, quando necessário. ${ }^{14}$

Com a emergência de Estados multiculturais e de formas políticas transnacionais, identidades distintas foram obrigadas a se relacionar como identidades igualmente legítimas, isto é, foi necessário que se encontrasse um espaço de coexistência para as identidades coletivas. A solução normativa do reconhecimento recíproco evita a verdadeira questão, pois pressupõe a igualdade de poder das reivindicações de identidade em situações reais. Tão logo se introduza a dimensão do poder, as soluções normativas não mais nos ajudam. Tem-se antes de prover instrumentos teóricos não em termos do que gostaríamos de ver, o que é certamente o reconhecimento recíproco de diferentes identidades, mas em termos das reais conseqüências que decorrem do desacoplamento entre as identidades coletivas e o Estado, isto é, o fim do monopólio da nação como narrativa criadora de identidade. É necessário, pois, que examinemos esta "marketização" (marketization) ${ }^{15}$ das identidades coletivas.

\section{O futuro do demos}

Venho argumentando que o desencantamento do Estado nacional, sua redução a um ator coletivo racional, não conduz ao desaparecimento do problema das identidades coletivas. Elas são simplesmente liberadas e podem exercer papéis muito diferentes. Ademais, a emergência de uma pluralidade de narrativas destrói o pertencimento exclusivo do povo ao Estado. O caráter contingente das narrativas nacionais abre a porta para o pluralismo e mesmo para a disputa entre narrativas. Em outras palavras, a dissociação entre a nação e o Estado transforma as identidades em narrativas que flutuam livremente. Em contrapartida, com a liberação das identidades, surge a necessidade de um novo tipo (ou de novos tipos) de comunidade para representá-las.

Se não a nação, o que estaria surgindo como um possível suporte para narrativas de identidade? Há um demos nascendo para além da nação? Ou temos de lidar com uma pluralidade de demoi ou com comunidades de tipo não-demos, ou, ainda, com a existência simultânea desses diferentes tipos? ${ }^{\text {16 }}$ Quais as opções para se construir uma comunidade que compartilhe uma narrativa e que esteja além do Estado nacional? Gostaria de distinguir três opções.

A primeira é a volta a comunidades prépolíticas, especialmente ao equivalente funcional das comunidades políticas, a saber, as comunidades religiosas tradicionais. Trata-se de um fenômeno bastante comum nas sociedades atuais. Os grupos sociais, particularmente aqueles com experiências migratórias ou coloniais, tendem a construir uma coletividade definida por algumas crenças religiosas compartilhadas. Essas crenças são tão mais fortes quanto mais possam estar inseridas em tradições religiosas canônicas, isto é, tradições religiosas com textos sagrados escritos.

A segunda pode ser considerada uma variante moderna da modalidade tradicionalista. Tratase da construção de novas comunidades religiosas que compartilham a experiência direta de seus participantes, não mediadas por autoridades presentes (como os grupos pentecostais, grupos de Novas Igrejas ou New Age). A diferença reside no fato de que, neste caso, o vínculo que une a comunidade é a experiência comum no "aqui e agora".

A terceira reside na construção de uma comunidade de interesses com uma identidade coletiva minimalista, isto é, uma comunidade constituída por pessoas que compartilham basicamente o interesse de a ela pertencer, definindo seus laços em termos de solidariedade aos que a ela pertencem. É isso, provavelmente, o que se entende por sociedade civil: um povo com uma identidade coletiva que, no curso de sua ação política, cria as condições para a existência de uma associação igual e livre.

Evidentemente, essa classificação não se refere apenas a tipos empíricos de construção de comu- 
nidades nas sociedades modernas. Pode-se inferir também, a partir dela, um aspecto normativo, visto que nem todas essas opções são compatíveis com uma política democrática. Assim, a opção por vínculos democráticos é possível, mas não há um argumento do por que tal opção possa acontecer e do por que não se realizaria uma outra.

Quais são as conseqüências dessas opções para os conflitos de identidade? No caso da opção tradicionalista, desencadear-se-á com facilidade a espiral de desentendimento e de autofechamento. Trata-se do melhor caminho para a guerra entre identidades coletivas. As comunidades tendem a uma reunificação do político e do comunitário, a um substituto direto e inflexível para o Estado nacional. Não é sem razão que os Estados nacionais a consideram uma ameaça real, não apenas militar, mas também cultural.

Quanto à segunda opção, a avaliação é mais difícil. As novas comunidades religiosas ou quase religiosas parecem ser apolíticas, uma vez que proporcionam nichos para o compartilhamento coletivo de uma experiência subjetiva. Tais nichos formam demoi pré-políticos, caracterizados por motivações sociais - solidariedade e responsabilidade comunitária -, e agrupam crentes que constroem sua identidade coletiva como uma emanação de uma experiência compartilhada. ${ }^{17}$ Esses grupos não contestam o Estado nacional, mas criam espaços transnacionais (e subnacionais) que escapam ao seu controle. Requerem de seus membros todas aquelas obrigações que o Estado nacional requer de seu povo: às obrigações para com o Estado (pagar impostos, enviar as crianças a escolas controladas pelo Estado, morrer pela nação, caso necessário) correspondem obrigações para com o grupo (dar apoio material à comunidade dos crentes, socializar as crianças nas crenças da comunidade, dar a vida pela comunidade, se for preciso). Assim, pode-se vislumbrar o surgimento de uma competição particular entre o Estado nacional e essas comunidades subnacionais ou transnacionais, politizando-as, mesmo que não intencionalmente. ${ }^{18}$ Trata-se do latente desfazer-se da nação, que contesta ou desafia o Estado nacional.

Por fim, a terceira opção baseia-se na idéia de que, em seu reconhecimento mútuo como concidadãos, os indivíduos criam laços frágeis entre si.
Essa idéia relaciona-se ao que considero identidade coletiva "fraca", pois as pessoas não são forçadas a acreditar em algo ou a compartilhar uma experiência coletiva de revelação. A única imposição é a de que aceitem as regras de procedimento do debate aberto e igual entre indivíduos portadores de interesses. Reiterando o já sugerido, isso envolve a idéia de uma sociedade civil que constrói sua identidade coletiva por meio de alguns códigos de interação civilizada entre seres humanos iguais e livres no interior de um espaço de interação social institucionalmente definido. Trata-se de uma exigência fraca, mas como kantiano, não conheço nenhum argumento pelo qual isso não possa ser suficiente. Como sociólogo, entretanto, sei que há outros que pensam ser preciso mais.

As conseqüências dessa opção são certamente menos beligerantes do que as da primeira. Elas são moderadoras por natureza. Se isso é o bastante para que ela sobreviva à competição com as outras construções de identidade, é uma questão que deixarei em aberto.

Há uma possível quarta opção, que funcionou em algumas partes do mundo, a saber, uma identidade forte baseada na tradição, na religião, em grandes vitórias políticas e no orgulho pelo passado imperial. Os impérios, contudo, desapareceram nos últimos cinqüenta anos: o britânico, o português, o espanhol, o holandês, o soviético; e antes desses, o otomano, o austro-húngaro e o prussiano, que desapareceram em um passado mais distante. ${ }^{19}$ Não precisamos lidar empiricamente com novos impérios, mas temos de tratar de novas formas de construção institucional - os "quase Estados" transnacionais.

Em vez de especular sobre possíveis cenários de construção e de mobilização de identidades na constelação pós-nacional (Habermas, 1998), podemos tomar uma outra linha interpretativa: examinar os casos existentes de instituições transnacionais que parecem seguir a opção da identidade "fraca".

Tenho em mente o caso da União Européia. Os fundamentos históricos e teóricos estão estabelecidos, o caso é claro e único. Acredito que a União Européia constitui um caso de experimentação com identidades "fracas" como um vínculo 
social para instituições políticas fortes. Trata-se de um laboratório em que o problema da construção e da mobilização de identidades encontrará um novo foco histórico. ${ }^{20}$ Quanto mais a construção política institucional se moverem direção a arranjos transnacionais, mais o Estado nacional se tornará um ator coletivo que não tem mais razão de ser em si mesmo, mas em seu papel de ator racional coletivo, forçado a participar de um jogo com outros Estados nacionais. O desencantamento do Estado nacional, transformado em ator coletivo racional, desloca a questão da identidade coletiva do âmbito da nação para o plano transnacional, onde são tomadas as decisões legais imperativas, e é preciso que surja uma identidade coletiva compatível para controlar essas instituições.

\section{Europa: um caso de identidade coletiva pós-nacional}

\section{Especificidade}

Na constelação "pós-nacional", a idéia de uma sociedade européia, e sobretudo a de uma identidade coletiva européia, parece ser algo atávica. O discurso sobre a Europa aparece, à primeira vista, como um discurso que tenta simplesmente traduzir o simbolismo nacional num simbolismo transnacional. Contudo, esta interpretação seria demasiado simplista, pois a idéia de uma unidade da Europa não é mais tão evidente como o foi a idéia de nação.

Confrontamo-nos com a busca de um denominador comum que difere do modelo que fundamenta a construção de uma identidade nacional. A busca de uma identidade européia é um exemplo da tentativa de se criar uma preocupação comum a partir de relações baseadas nos interesses dos cidadãos. Esses interesses, que dão forma às relações sociais, têm uma dupla natureza: são materiais mas também ideais (como formulou Max Weber). A Europa é mais do que a "Europa do burguês". Entretanto, é difícil definir este "mais", pois não há um referente real. A solução teórica desse paradoxo é a radicalização da idéia de integração social por meio da comu- nicação: a ordem social surge onde os indivíduos levantam suas vozes e lutam para serem ouvidos. Interesses ideais têm a ver com idéias, e estas existem numa forma lingüística: são as referências ao mundo exterior contidas nos símbolos. As referências ao mundo podem envolver mobilizações diferenciadas de carga simbólica. Há áreas em que o elemento comunicativo exerce um papel mais propriamente secundário. Tais são as questões distributivas. Em que medida a mobilidade social deve ser estimulada, que direitos sociais as pessoas devem ter, são questões que podem ser tratadas com habilidades comunicativas medianas. Interesses não requerem muita interpretação, nem precisam de muita compreensão (Verstehen). As questões distributivas são solucionadas nos jogos estratégicos de conceder e negar. Há um "bolo", e os nele interessados têm de maximizar sua distribuição igualitária. Em contrapartida, as questões relativas à identidade e à diferença necessitam de uma maior ação comunicativa. A identidade existe apenas por ser verbalizada e, portanto, essas questões só podem ser vislumbradas a partir da comunicação e da compreensão. Isso explica por que uma língua comum foi tão importante na construção das identidades nacionais. O sentimento de união mediado por vínculos sociais pressupõe uma língua compartilhada.

Mas, esse terreno cultural comum não ocorre na Europa. Nem mesmo podemos invocar a dominância da língua inglesa, quando consideramos o papel do francês em questões administrativas ou a importância cada vez maior do espanhol no mundo globalizado. Não pode haver integração cultural com a ausência do meio, isto é, de uma língua comum. A europeização da cultura, portanto, transferiu-se para outros meios de comunicação, como a música, a linguagem pictórica, o reconhecimento de símbolos por meio dos filmes, da televisão e da publicidade. Essa forma de criação de significado produz uma cultura comum para além das culturas separadas por línguas nacionais. E, ainda assim, isso não servirá de base para a formação de uma identidade européia. Onde coincidem, a cultura lingüística e as formas simbólicas de comunicação se reforçam 
reciprocamente. O exemplo histórico é o do nacionalismo como um movimento cultural que reuniu a comunidade lingüística e a comunidade simbólica e, assim, foi capaz de criar claros elementos de distinção em relação ao mundo exterior. Onde não houve coincidência, a Europa encontrou problemas.

Para evitar esse bloqueio cultural, a integração européia tomou o caminho da integração econômica. O objetivo foi criar condições para uma efetiva barganha de interesses. ${ }^{21}$ Desde Maastricht, o objetivo tem sido encontrar esse espaço com base em uma identidade "fraca", definida seja em termos políticos, seja em termos culturais. Contudo - e aqui retomo meu argumento -, a abertura ao debate sobre identidade "fraca" significou também o retorno às disputas por identidades fortes. ${ }^{22}$

\section{A volta das identidades fortes na Europa: uma terceira proposta teórica}

Tão logo seja superada a pura barganha de interesses e estes estejam ligados a formas simbólicas coletivamente compartilhadas, a dupla face da cultura torna-se visível, provocando dissenso. Esse é finalmente inevitável porque a barganha de interesses não pode ficar restrita a puros interesses. Ela se mistura com motivações que têm a ver com a proteção de uma identidade coletiva. Discutirei dois mecanismos que levaram a mobilizar fortes identidades coletivas na Europa. O primeiro diz respeito ao Estado de bem-estar social.

A íntima conexão entre idéias e interesses caracteriza a lógica nacionalista envolvida na defesa do Estado nacional de bem-estar social na Europa. A experiência de ser um competidor no mercado de direitos sociais conduziu não só ao fechamento de identidades grupais específicas, mas a uma dinâmica do cultivo da distância em relação às outras e a sua desvalorização cultural. O Estado nacional de bem-estar social revela-se uma barreira à integração européia, pois restabelece o modelo de Estado-nação e, com ele, a busca por uma identidade coletiva forte o suficiente para proporcionar a solidariedade necessária a um Estado com tal característica. Isso colide com reivindicações igualmente fortes de outros tipos de identidade coletiva. Assim, a integração européia estimula o ressurgimento da questão étnica na esfera nacional.

A segunda revivescência de identidades fortes é uma reação direta à busca de uma identidade européia fraca. O resultado das tentativas de pensar uma identidade européia foi - paradoxalmente - o de marcar limites em todos os níveis, particularmente nos níveis regionais. Redescobrem-se símbolos de fronteiras regionais e de relações locais; identidades regionais são revitalizadas e contrapostas a formas de integração nacionais e supranacionais. A Europa das "comunidades étnicas" constitui uma tentativa de restaurar fronteiras simbólicas que a memória nacional já esquecera. Mesmo com um século de "comunismo", a imposição de ideologias destradicionalizantes na Europa do Leste não teve êxito na produção desse esquecimento. Para além das fronteiras nacionais, são redescobertas novas fronteiras simbólicas contra o "outro": a defesa do Oeste, o Ocidente, a Cristandade. O dissenso é provocado pela alteridade, por um consenso cultural concorrente que, no caso mais acentuado, deve ser explicado por diferenças religiosas, no mais superficial, por diferenças estéticas, e no mais usual, por diferenças sociais.

O novo etnonacionalismo, surgido especialmente nos países do Leste europeu, não permite mais distinguir entre diferenças primordiais e artificiais. Esse sentimento re-mobiliza velhas marcas e projeta novas fronteiras simbólicas. Renascem "antigos" significados, nos quais o "antigo" é repensado e enriquecido com novos atributos. O "antigo" é apenas um meio para a alegação de uma comunalidade, um gatilho para a barganha coletiva que, no curso de sua realização, se dissocia daquilo que a desencadeou. Nesse processo, os símbolos da comunalidade original são ulteriormente transformados, a ponto de perderem a conexão com o mundo real. Tornam-se mera construção social. O regionalismo, que surgiu em algumas sociedades do Ocidente europeu, apresenta um padrão similar: sua referência a lealdades primordiais é cada vez mais uma con- 
strução de difícil sustentação contra o esquecimento institucional.

Dessa forma, passa a ser contestável a expectativa de uma teoria de modernização que presume a convergência do particular para o universal no desenvolvimento da sociedade moderna. Tornou-se obsoleta até mesmo a variante crítica que viu no colonialismo e no imperialismo os elementos destrutivos da diversidade cultural. O particular prevalece sobre esse poder destrutivo e, ao mesmo tempo, destrói o culturalmente outro. A perspectiva otimista do Iluminismo com relação à idéia de racionalidade, exercida na intercomunicação dos indivíduos livres e iguais, é demolida pela experiência do fechamento da comunicação, da exclusão por meio da comunicação e da redução desta a formas interativas empobrecidas. O apoio intelectual para isso é fornecido pela ênfase na diversidade cultural e seu uso como um argumento contra o universalismo.

Contudo, a integração européia prossegue. Apesar da divisão da Europa em unidades culturais com identidades particulares, observa-se o aumento da interação baseada em interesses. O estágio atual do desenvolvimento da integração européia caracteriza-se por uma situação paradoxal: heterogeneidade cultural e, ao mesmo tempo, homogeneidade baseada em interesses.

Qual é a solução buscada para esse paradoxo? Primeiramente, tentou-se construir um contexto para coordenar interesses econômicos; em seguida, a busca voltou-se para a formação de uma identidade européia. A primeira resposta não é suficiente, uma vez que interesses necessitam restrições legítimas, isto é, restrições aceitas por todos. A segunda pode ser considerada até mesmo perigosa porque, por trás da ilusão harmonizadora da existência de laços culturais na Europa, oculta-se a lógica perversa das construções identitárias fortes. ${ }^{23}$

\section{Discussão em torno de uma proposta alternativa}

Haveria uma forma de integração social situada entre a barganha de interesses e o con- senso cultural, entre a ruptura da comunicação e o ideal de uma harmonia comunicativa, uma forma de integração social que não se baseasse apenas no benefício recíproco, tampouco na necessidade de valores compartilhados? Essas questões estão subjacentes à idéia de que a elaboração de uma constituição pode ser um projeto gerador de identidade (esta é a idéia do patriotismo constitucional ${ }^{24}$ ). Se assim fosse, teríamos um caso de identidade coletiva fraca. Mas, para isso, será preciso não só que se forme essa espécie de identidade constitucional, mas também que ela crie vínculos fracos entre os povos europeus. Com isso, talvez pudéssemos responder se o demos, que era uniforme e homogêneo no contexto do Estado-nação, seria substituído por uma pluralidade de demoi, que compartilhasse a crença em uma constituição para a regulamentação da vida conjunta. Nesse caso, teríamos muitos demoi compartilhando tãosomente a idéia daquilo que torna um povo um demos. O que os uniria seria uma narrativa antiga e particularmente "fraca": a narrativa da cidadania como tal. ${ }^{25}$

\section{Conclusão}

Para concluir, algumas considerações sobre os problemas levantados no curso desta argumentação. Discutimos primeiramente o paradoxo contido na idéia do Estado nacional que se desencanta ao tornar-se um ator coletivo racional, um grupo de interesse em escala global, e, ao mesmo tempo, se re-encanta com a pluralização de reivindicações de identidades coletivas em seu interior, opondo identidades nacionais a outras identidades, o que o transforma em cenário de formas mais ou menos violentas de mobilização de identidades.

Analisamos também os riscos relacionados à evolução dos acontecimentos que giram em torno dessa transformação do Estado nacional. Quando os sentimentos nacionais são postos contra outros sentimentos coletivos, o Estado nacional certamente se enfraquece ainda mais, uma vez que deve assumir o arriscado papel de garantir um 
espaço onde a identidade nacional possa se defrontar com outras reivindicações de identidade. Há muitas identidades coletivas convivendo no Estado, as quais, no curso de seu re-encantamento, entrarão na espiral viciosa da mobilização de identidades.

É de fato possível domesticar os sentimentos coletivos? O desencantamento do Estado nacional conduziu à desconexão entre o modo de pertencer e os sentimentos de união, entre a filiação ao Estado e a identidade coletiva. Isso abre caminho a uma concepção diferente de identidade coletiva, qual seja, uma identidade fraca baseada na filiação e fundada na crença em garantias constitucionais de direitos (e obrigações) a ela associados. Por conseguinte, uma identidade que se consubstancia em uma narrativa altamente secular: a narrativa da própria cidadania. Aí reside a importância do debate sobre a "cidadania européia”, que é uma construção de identidade coletiva fraca.

Por fim, como exemplifica o caso europeu, nem mesmo instituições de tipo estatal com identidades fracas geram um mundo para além do poder. Mas, nessas circunstâncias, a formação de identidades para a ação coletiva pode tornar-se mais fácil e não permanecer atada à lógica perversa da mobilização de identidades em sentido próprio. A disputa entre detentores de poder e movimentos que os desafiam é inevitável, mas acredito que se possa evitar becos sem saída nesse tipo de conflito, como o risco da mobilização de identidades em sentido próprio que caracterizou a trajetória histórica do Estado-nação.

A Europa, na realidade, é mais uma vez um laboratório histórico onde os paradoxos são abundantes e desafiam a imaginação teórica.

\section{NOTAS}

1 A China é um caso em que ainda se mantém a estrutura de um império, cujas partes, entretanto, não constituem unidades que possam ser consideradas embriões de Estados nacionais emergentes. Taiwan, por outro lado, mesmo dentro daquela estrutura, aponta para essa opção.
2 A discussão sobre demos ganhou proeminência no interior do debate sobre a construção da nova Europa. Para um levantamento sistemático a respeito dessa questão na Europa, ver Lepsius (1990) e Weiler (1995). Este debate foi mais desenvolvido em Abromeit (1998) e Abromeit e Schmidt (1999).

3 Essa lógica foi explicitada em diferentes tradições teóricas. Ver, especialmente, Hardin (1994), para uma explanação racionalista do conflito de grupo.

4 O processo de construção da nação é um lócus clássico da sociologia histórica. Ver Kriesi (1999) ou o trabalho clássico de Rokkan (1999).

5 Esse processo de acoplamento foi também instrumentalizado por regimes não democráticos, com elevados custos e resultados fracassados, como mostram os casos da Alemanha, da Itália, da Espanha, de Portugal, da Europa do Leste e da América Latina.

6 A inclusão de trabalhadores, mulheres e minorias étnicas é um dos resultados do processo de modernização política, dada a resistência dos grupos dominantes em conceder tais direitos. O debate sobre a cidadania tornou-se um importante tópico da análise sociológica nos anos recentes. Ver os trabalhos clássicos de Marshall (1950) e Bendix (1977). Para um maior desenvolvimento a esse respeito, ver Brubaker (1992), Tilly (1996), Crouch, Eder e Tambini (2001) e Eder e Giesen (2001). Uma boa visão geral do assunto encontra-se em Kymlicka e Norman (1995) e Turner (1993).

7 Trata-se de códigos primordiais, que naturalizam as diferenças, códigos tradicionalistas, que ancoram a identidade na memória do passado, e códigos universalistas, que ligam a identidade coletiva a uma vocação universal de um povo. Para esta distinção, ver Eisenstadt e Giesen (1995) e Giesen (1998).

8 Para uma versão sociopsicológica deste argumento, ver Jenkins (1996, 1997).

9 Esta busca racional de interesses foi identificada por North como a causa da dinâmica particular da sociedade européia desde o século XII (cf. North e Thomas, 1971; North, 1990).

10 A distinção das identidades como opostas a interesses foi analisada de maneira particularmente 
esclarecedora por Pizzorno (1986). As idéias apresentadas muito devem a essa análise.

11 Não há, em português, um equivalente preciso para appropriateness, que é a qualidade de ser apropriado (adequado, próprio, conveniente). A expressão "lógica da appropriateness" tem a ver com a idéia de regras definidoras do que pode ser considerado apropriado pelos atores envolvidos numa determinada situação. "Numa metáfora do dever [por oposição a uma metáfora da escolha], presumimos que os atores [...] associam certas ações com certas situações por meio de regras de appropriateness. O que é apropriado para uma determinada pessoa numa situação particular é definido pelo sistema político e pelo sistema social, e transmitido por meio da socialização" (cf. March e Olsen, 1989, p. 741).

12 A melhor explicação desta noção encontra-se em Giesen (1998).

13 É difícil Ter um domínio completo sobre a profusa literatura a respeito da União Européia. Sobre seu caráter multi-nível, ver especialmente Kohler-Koch e Eising (1999).

14 O papel social das narrativas foi enfatizado por Somers em seu trabalho histórico-sociológico sobre a cidadania na Inglaterra a partir do século XVII (cf. Somers, 1993, 1995)

15 "Marketização" significa simplesmente que a narrativa tem de competir num mercado onde as narrativas são ofertadas. Esse mercado deve ser tão mais esperado quanto os fluxos de comunicação possam cruzar as fronteiras nacionais, e os meios de comunicação de massa e a educação ofereçam acesso a diversas espécies de narrativas. Para uma análise desse conceito, ver Crouch, Eder e Tambini (2001).

16 Comunidades de tipo demos são as que têm seu fundamento na vontade comum. Comunidades que não possuem demos são as que se baseiam em algo que está fora e acima da comunidade, em última instância em Deus ou em algo equivalente. Para uma discussão a esse respeito, ver Abromeit (1998).

17 Ela se funda, aliás, não em Jesus, mas no Espírito Santo!

18 O primeiro indicador desse fato é a intensidade com que a cientologia é policiada em muitas partes da Europa.
19 É preciso esperar pelo que acontecerá com o império chinês, o último a sobreviver. Ver conclusão em Eder e Giesen (2001).

20 Para uma exploração dessa tese, ver Eder e Giesen (2001).

21 Isso se reflete no que foi chamado de "teorias de integração", que explicam a integração européia variando de teorias realistas a teorias funcionalistas. Apenas recentemente, as teorias normativas ganharam terreno em relação a essas teorias clássicas. Para uma interessante discussão a esse respeito, ver Lepsius (2001).

22 Sobre a idéia de "identidades coletivas fracas" como um modelo para uma identidade européia, ver Eder (2001).

23 Para uma crítica da noção de uma identidade européia em virtude de seus conteúdos ideológicos, ver Sträth (2002).

24 Essa idéia foi proposta e popularizada por Habermas (1992, 1998), todavia, recebeu duras críticas tanto de autores que a consideram muito frágil como cimento para as sociedades, como de outros que a consideram muito forte para manter coesa uma sociedade pós-tradicional.

25 Tomei de Margaret Somers (1993, 1995) a idéia de considerar a própria cidadania uma narrativa.

\section{BIBLIOGRAFIA}

ABROMEIT, Heidrun. (1998), Democracy in Europe: legitimizing politics in a NonState Polity. Oxford, Berghahn.

ABROMEIT, Heidrun \& SCHMIDT, Thomas. (1999), "The riddle of borderless democracy: on the search of transnational demoi", mimeo.

BENDIX, Reinhard. (1977), Nation-Building and citizenship: studies of our changing social order. Berkeley, CA, University of California Press.

BRUBAKER, William Rogers. (1992), Citizenship and nationbood in France and Germany. Cambridge, MA, Harvard University Press. 
CROUCH, Colin; EDER, Klaus \& TAMBINI, Damian (eds.). (2001), Citizenship, markets, and the State. Oxford, Oxford University Press.

EDER, Klaus. (2001), "Integration through culture: the paradox of the search for a European identity", in Klaus Eder e Bernd Giesen (eds.), European citizenship: national legacies and postnational projects, Oxford, Oxford University Press, pp. 222-244.

EDER, Klaus \& GIESEN, Bernd (eds.). (2001), European citizenship: national legacies and postnational projects, Oxford, Oxford University Press.

EISENSTADT, Shmuel N. \& GIESEN, Bernhard. (1995), "The construction of collective identity". Archives Européennes de Sociologie, 36: 72-102.

GIESEN, Bernhard. (1998), The intellectuals and the nation: collective identity in German Axial age. Cambridge, Cambridge University Press.

HABERMAS, Jürgen. (1984), The theory of communicative action (vol. 1: Reason and the rationalization of society). Boston, MA, Beacon Press.

(1987), The theory of communicative action. (vol. 2: Lifeworld and system: a critique of functionalist reason. Boston, MA, Beacon Press.

. (1992). "Citizenship and national identity: some reflections on the future of Europe". Praxis International, 12: 1-19.

(1998), Die postnationale Konstellation. Politische Essays. Frankfurt/Main, Suhrkamp.

HARDIN, Russell. (1994), One for all: the logic of group conflict. Princeton, NJ, Princeton University Press.

JENKINS, Richard. (1996), Social identity. Londres, Routledge.
(1997), Retbinking ethnicity: arguments and explorations. Londres, Sage.

KOHLER-KOCH, Beate \& EISING, Rainer (eds.). (1999), The transformation of governance in the European Union. Londres, Routledge.

KRIESI, Hanspeter. (1999), "Introduction: State formation and nation building in the Swiss case", in Klaus Armingeon, Hanspeter Kriesi, Hannes Siegrist e Andreas Wimmer (eds.), Nation and national identity: the European Experience in perspective, Zurich, Seismo, pp. 13-28.

KYMLICKA, Will \& NORMAN, Wayne. (1994), "Return of the citizen: a survey of recent work on citizenship theory". Ethics, 104: 352-381.

(1995), Return of the citizen: a survey of recent work on citizenship theory, in Ronald Beiner (ed.), Theorizing citizenship, Albany, NY, State University of New York Press, pp. 283-322.

LEPSIUS, M. Rainer. (1990), “'Ethnos oder Demos'. Zur Anwendung zweier Kategorien von Emerich Francis auf das nationale Selbstverständnis der Bundesrepublik und auf die Europäische Vereinigung", in , Interessen, Idee und Institutionen. Aufsätze zur Makrosoziologie, Opladen, Westdeutscher Verlag, p. xx.

. (2001), "The European Union: economic and political integration and cultural plurality", in Klaus Eder e Bernd Giesen (eds.), European citizenship: national legacies and postnational projects, Oxford, Oxford University Press, pp. 205-221.

MARCH, James G. \& OLSEN, Johan P. (1984), "The new institutionalism: organizational factors in political life". American Political Science Review, 78: 734-739. 
(1989), Rediscovering institutions: the organizational basis of politics. Nova York, The Free Press.

MARSHALL, Thomas H. (1950), Citizenship and social class. Cambridge, MA, Cambridge University Press.

NORTH, Douglass C. (1990), Institutions, institutional change and economic performance. Nova York, Cambridge University Press.

NORTH, Douglass C. \& THOMAS, Robert. (1971), The rise of the Western World: a new economic bistory. Cambridge, Cambridge University Press.

PIZZORNO, Alessandro. (1986), "Some other kinds of otherness: a critique of 'rational choice' theories", in Alexandro Foxley, Michael S. McPherson e Guillermo O'Donnell (eds.), Development, democracy and the art of trespassing: essays in bonor of Albert O. Hirschman, Notre Dame, IN, University of Notre Dame Press, pp. 355-373.
ROKKAN, Stein. (1999), State formation, nation building, and mass politics in Europe: the theory of Stein Rokkan. Oxford, Oxford University Press.

SOMERS, Margaret R. (1993), "Citizenship and the place of the public sphere: law, community, and political culture in the transition to democracy". American Sociological Review, 58: 587-620.

(1995), "Narrating and naturalizing civil society and citizenship theory". Sociological Theory, 13: 221-265.

STRÅTH, Bo. (2002), "A European identity: to the historical limits of a concept". European Journal of Social Theory, 5: 387-401.

TILLY, Charles (ed.). (1996), Citizenship, identity and social bistory. Cambridge, Cambridge University Press.

TURNER, Bryan S. (ed.). (1993), Citizenship. Londres, Routledge, 3 vols.

WEILER, Joseph H. H. (1995), "Does Europe need a constitution? Reflections on demos, telos and the German Maastricht decision”. European Law Journal, 1: 219-258. 


\section{IDENTIDADES COLETIVAS E MOBILIZAÇÃO DE IDENTI- DADES}

\author{
Klaus Eder
}

Palavras-chave

Estado; Nação; Identidade; Povo; Globalização

Os Estados nacionais contemporâneos precisam reproduzir identidades coletivas em sociedades que apresentam crescentes diferenças étnicas. Nessa situação, a ordem política se desacopla da comunidade do povo. Tal circunstância suscita questões como as seguintes: $O$ que acontece com os sentimentos de fazer parte da nação? Como se apresentam as identidades coletivas desacopladas do Estado nacional? Referemse ainda a uma comunidade, situada abaixo ou acima do Estado nacional, ou surge uma espécie de sentimento de união mais abstrato ou mais instrumental? O que acontece com a mobilização política nessas sociedades culturalmente diversificadas? E uma última questão: ainda precisamos do Estado nacional para domesticar os sentimentos coletivos ou será preciso imaginar formas diferentes, que exigem novos instrumentos teóricos, com vistas a descrever e conceber instituições para tal fim?

\section{COLLECTIVE IDENTITIES AND IDENTITY MOBILIZA- TION}

Klaus Eder

Key words

State; Nation; Identity; People; Globalization

Contemporary nation states have to reproduce collective identities in societies with increasing ethnic differences. This is the situation where the political order is decoupled from the community of people. The following questions arise in such a situation: What happens to the sentiments of national belonging? How do collective identities decoupled from the nation-state look like? Do they still refer to a community below or above the nation-state or does emerge a more abstract or a more instrumental kind of togetherness? What happens to political mobilization in such culturally diversified societies? The final question: Do we still need the nation-state for taming collective sentiments or do we have to imagine different forms which require new theoretical tools to describe and design institutions for taming collective sentiments?

\section{IDENTITÉS COLLECTIVES ET MOBILISATION D'IDENTITÉS}

\author{
Klaus Eder
}

\author{
Mots-clés \\ État; Nation; Identité; Peuple; \\ Globalisation
}

Les États contemporrains doivent reproduire des identités collectives de sociétés qui présentent des différences ethniques croissantes. Dans ce cas, l'ordre politique se détache de la communauté du peuple. Une telle circonstance suscite certaines questions comme, par exemple: que deviennent les sentiment d'appartenir à une nation? De quelle façon se présentent des identités collectives détachées de l'État? Est-ce qu'elles se réfèrent toujours à une communauté située en-dessous ou au-dessus de l'État, ou est-ce qu'apparait une sorte de sentiment d'union plus abstrat ou plus instrumental? Que devient la mobilisation politique dans ces sociétés culturellement diversifiées? Et une dernière question: avons-nous toujours besoin de l'État pour apprivoiser les sentiments collectifs ou est-ce que l'on doit imaginer des manières différentes qui exigeraient de nouveaux instruments théoriques, pour décrire et concevoir des institutions qui nous permettent cela? 